\title{
Answer and discussion paediatric neuroimaging quiz case
}

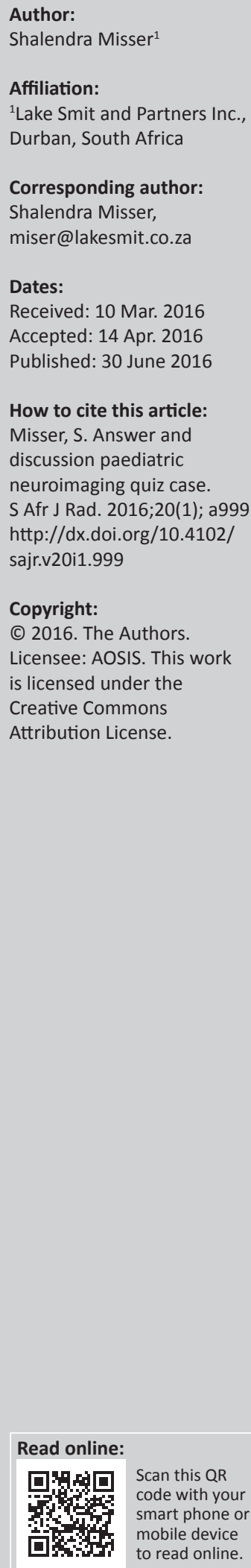

A three-and-a-half-year-old male child was referred for neuroimaging under general anaesthesia for intractable seizures. A final diagnosis of probable tuberous sclerosis with associated left hippocampal sclerosis was made. Differential diagnosis of malformation of cortical development with hippocampal sclerosis (Type 3a) was considered with respect to the left temporal lobe abnormality. It is heartening to note that several good submissions were received for the paediatric quiz case. Noteworthy responses were received from Dr Samuel Mannikam, Dr Thandi Buthelezi, Dr Philip Janse van Rensburg and Dr Ian Haynes, however, the prize of R2000 was awarded to Dr Richard Busayo Ulatunji for the most inclusive answer.

\section{Curse of the chromosome: Convulsions, cutaneous and cognitive clinical syndrome}

A three-and-a-half-year-old male child was referred for neuroimaging under general anaesthesia for intractable seizures. Figures 1, 2, 3, 4, 5 and 6 are the selected MR images.

\section{Answer}

The child referred for imaging in this case was significantly debilitated by the intractable seizures he suffered. The convulsions were predominantly tonic-clonic in nature, while some were focal with secondary generalisation. We were fortunate to obtain a good quality MRI study under general anaesthesia in a seizure-free interval. The axial T2-weighted image (Figure 1) shows left frontal cortical swelling with hyperintensity due to hamartomatous cortical-subcortical tubers. One tuber is also noted at the postero-superior right parietal lobe in the angular gyrus.

Figure 2 is an axial FLAIR sequence image demonstrating numerous transmantle radial migration lines as hyperintense bands. These lines traverse the white matter from the ventricular ependymal surface to the subcortical white matter. One such band in the right frontal lobe is associated with a cortical-subcortical tuber as are two further bands in the postero-inferior parietal lobes on both sides.

There are several abnormalities depicted in Figure 3 which is a coronal FLAIR sequence image. Firstly, there are several subtle hyperintense cortical hamartomas. One of these at the left temporal lobe is contiguous with a transmantle radial band which extends up to a hyperintense left hippocampal formation. The margins of the hippocampus are indistinct and the appearance may be due to recurrent seizure activity or concomitant mesial temporal sclerosis. Also noted are several subependymal nodular foci probably representing subependymal tubers. These are of higher signal when compared to the cerebral cortex and are therefore unlikely to represent nodular heterotopia.

Figures 4 and 6 are coronal T1- inversion recovery sequence images and Figure 5 is a coronal T1weighted image - all three confirming that the subependymal nodules are probably tubers. Also further delineating the cortical-subcortical hamartomas, left hippocampal signal abnormality and adjacent transmantle left temporal lobe band.

Magnetic resonance angiogram (MRA) was performed to ensure that the circle of Willis (Figure 7) was intact with no evidence of vasculopathy, particularly childhood vasculitis or transient cerebral arteriopathy. The MRA was normal, and importantly no aneurysms were noted.

A final diagnosis of probable tuberous sclerosis (TS) with associated left hippocampal sclerosis was made. Differential diagnosis of malformation of cortical development (MCD) with hippocampal sclerosis (Type 3a) was considered with respect to the left temporal lobe abnormality. 


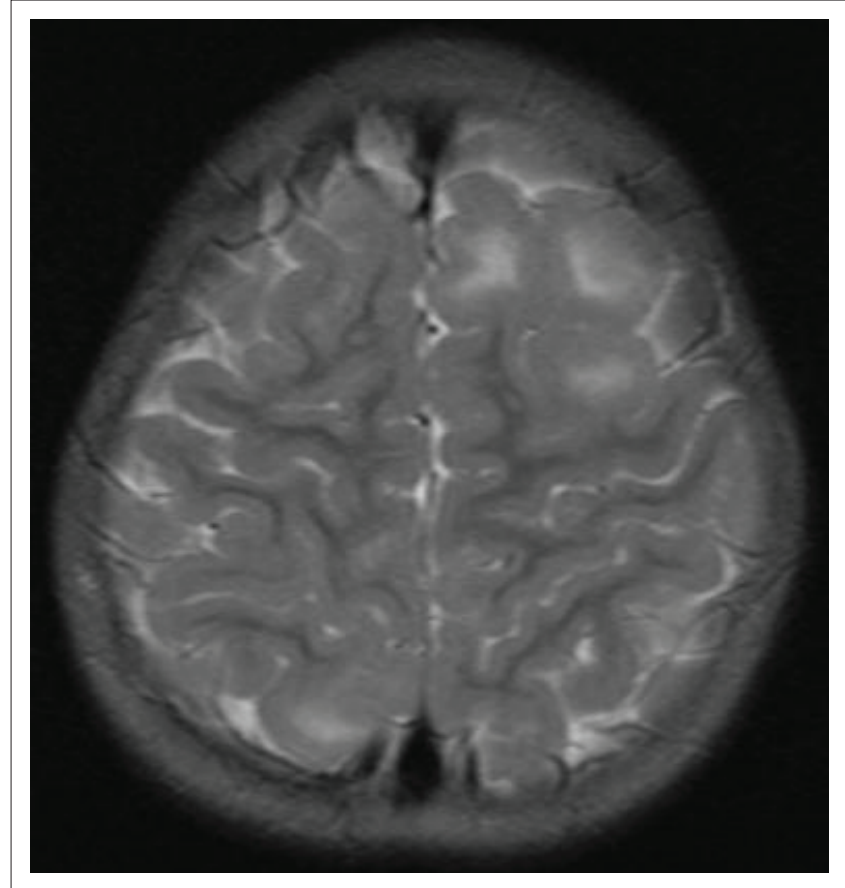

FIGURE 1: Axial T2-weighted MR image.

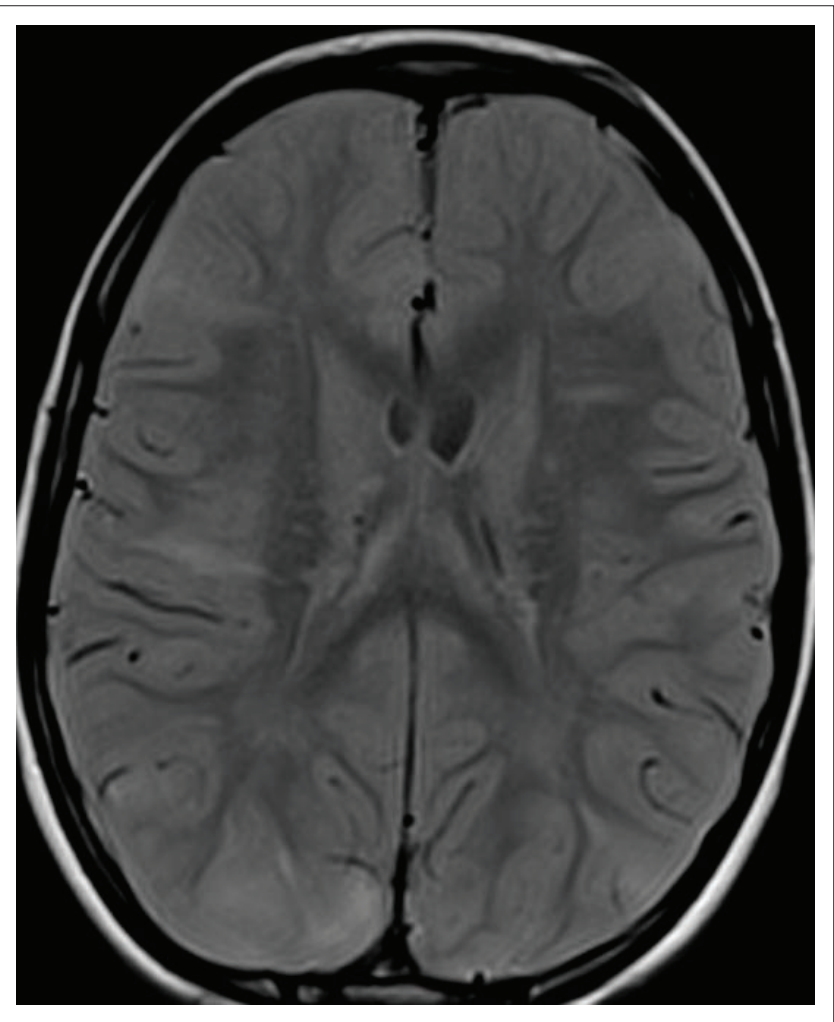

FIGURE 2: Axial FLAIR MR image.

\section{Discussion}

TS is a neurocutaneous syndrome with protean manifestations involving several organ systems. TS is the second most common neurocutaneous syndrome after neurofibromatosis type 1 and has been documented since the late 1800s. Also known as Bourneville disease or TS complex, this disease has a variable prevalence according to sampled

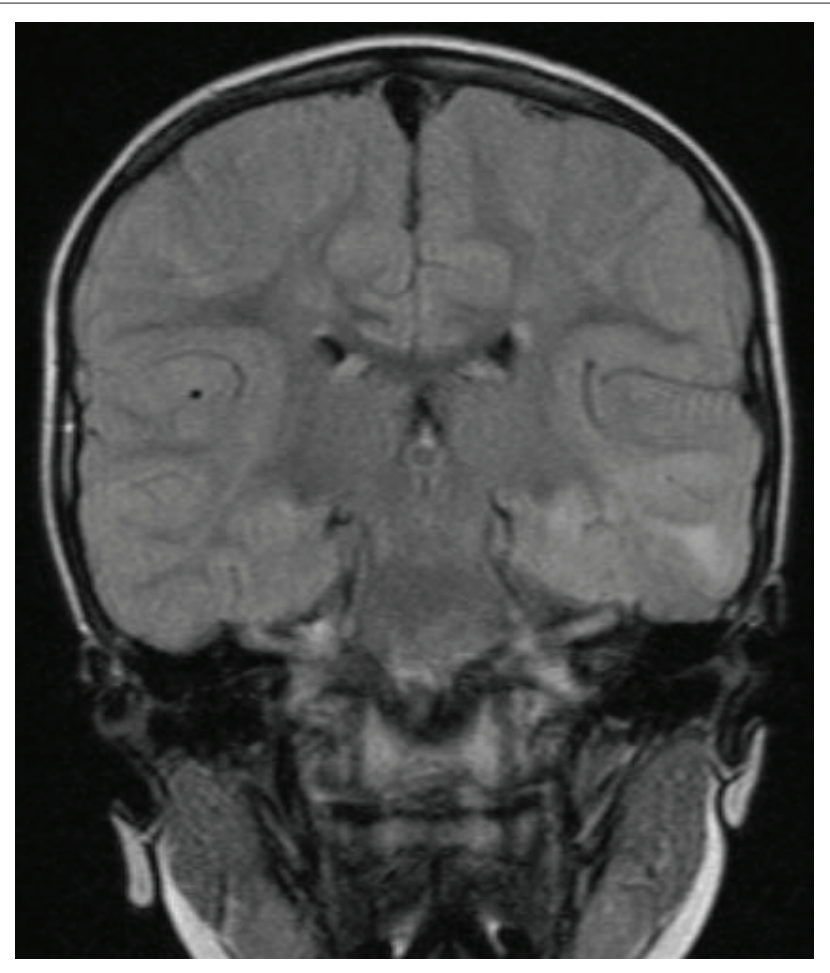

FIGURE 3: Coronal FLAIR MR image.

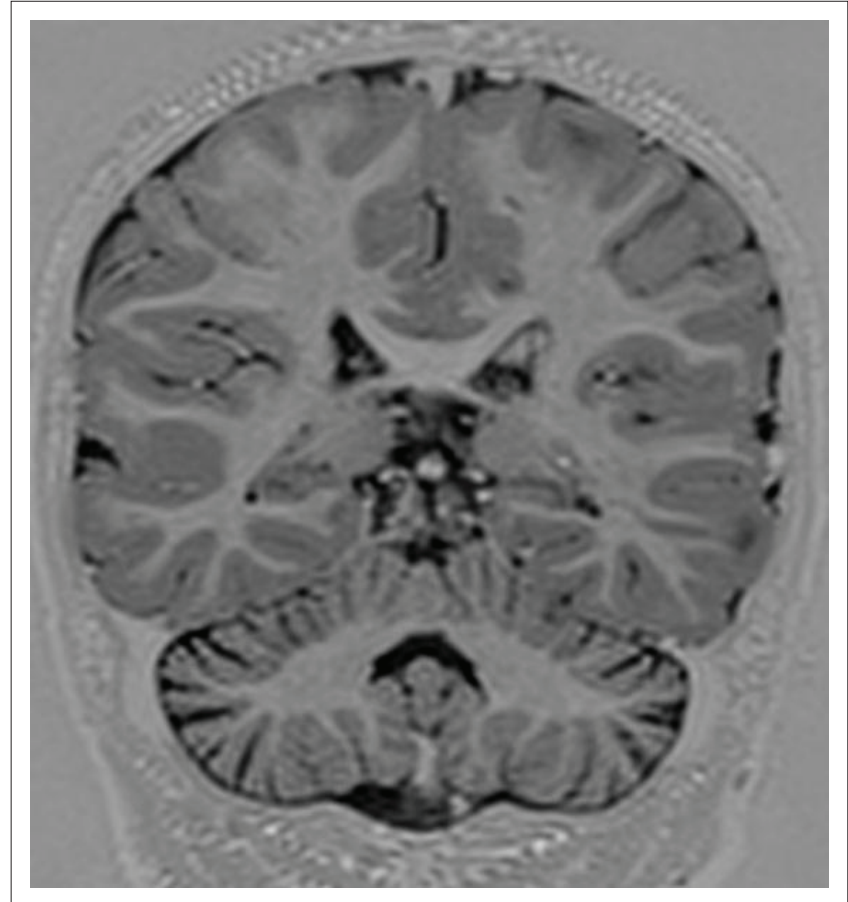

FIGURE 4: Coronal T1-inversion recovery MR image.

population groups from 1:6000 to 1:12 000. ${ }^{1}$ There is no gender predilection. Sporadic cases are reported to occur in up to $70 \%$ of patients while autosomal dominant inheritance is noted in $30 \%$. The underlying pathophysiology is thought to be due to a genetic predisposition with two major genes that interplay in a series of complex relationships. TSC1 gene located on chromosome band 9q34, which codes for the protein hamartin, and TSC2 gene located on chromosome 
band 16p13.3, which codes for the protein tuberin, are tumour suppressor genes. Failure of the TSC1-TSC2 protein complex, due to inactivation of the genes, results in upregulation of the mammalian target of rapamycin (mTOR) pathway. This leads to the phenotypic abnormalities predominantly of benign tumours of embryonic ectodermal origin.

The classically described Vogt triad, comprising adenoma sebaceum/skin lesions, seizures and mental retardation is only encountered in a third of patients. Radiological investigations demonstrate valuable supplementary features, particularly intracranial manifestations, that aid in making a diagnosis. Table 1 outlines the major and minor features encountered in TS. ${ }^{2}$

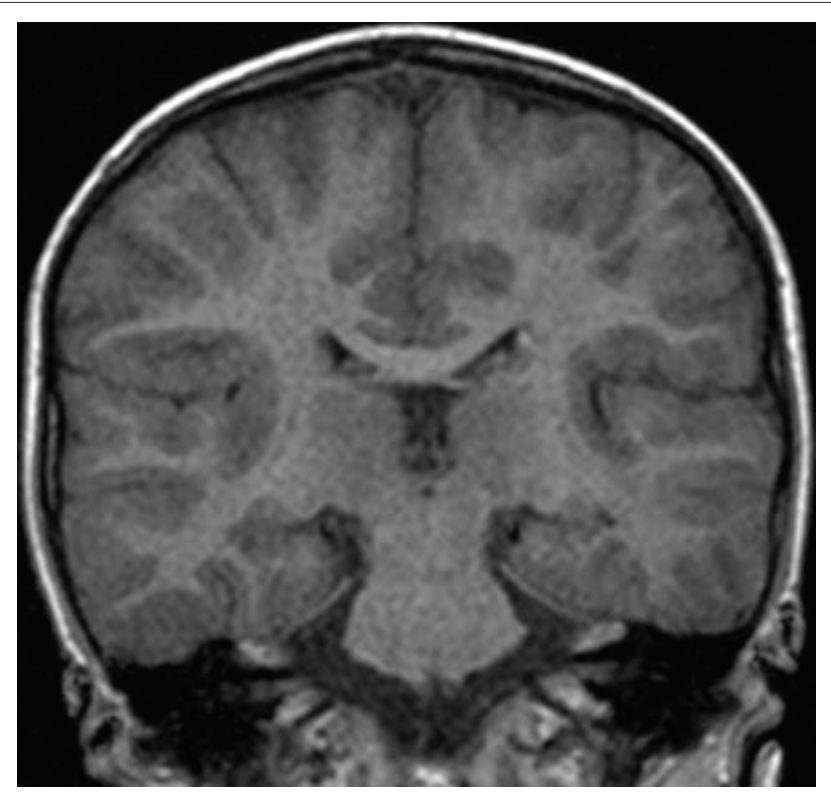

FIGURE 5: Coronal T1-weighted MR image.

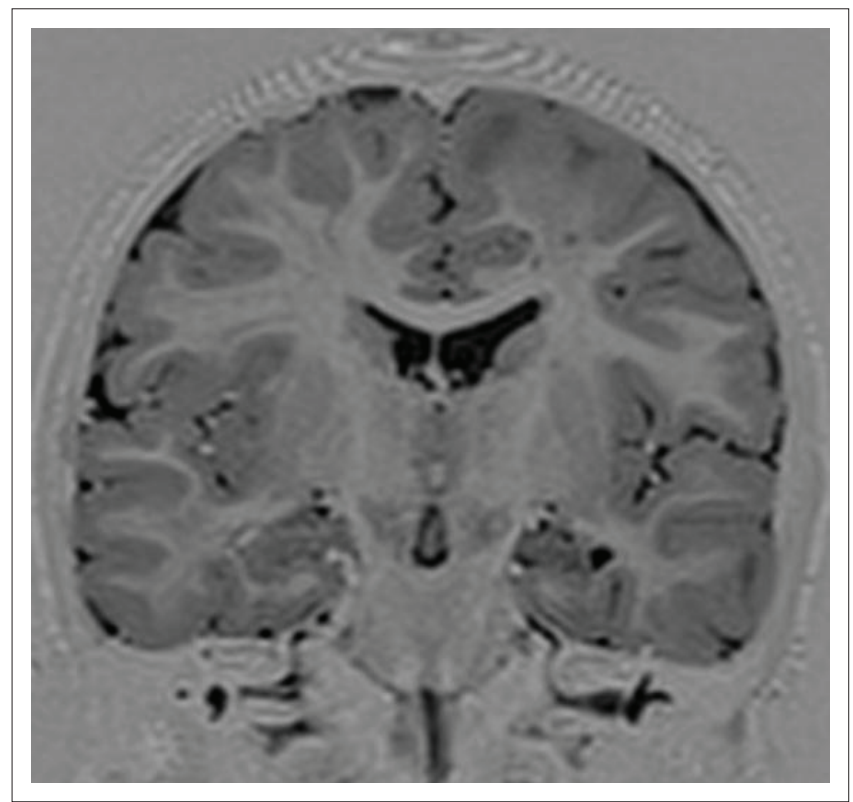

FIGURE 6: Coronal T1 inversion recovery MR image.
The neurocognitive morbidity associated with TS accounts for the clinical presentation in a large number of patients. Approximately $90 \%$ of patients present with seizures. Autism spectrum disorder and intellectual disability are the other frequent neurological sequelae of TS. Table 2 describes the clinical syndromes associated with neurological manifestations of TS including three of which are major criteria for the diagnosis. These lesions have been extrapolated to the schematic drawing in Figure 8.

Cortical tubers are hamartomas comprising glial, neuronal elements as well as giant cells with abnormal lamination of the cortex. Loss of grey-white matter differentiation and bulging of the cortex may be noted. Gallagher et al. ${ }^{3}$ described three subtypes of tubers with variable MRI appearance associated with different phenotypic and/or clinical presentations as annotated in Table 3. In neonates, the hamartomatous tubers may be undetectable on T2-weighted sequences due to similar relaxation time to premyelinated cerebrum and may only be seen on T1-weighted imaging. ${ }^{4}$ Contrast enhancement,

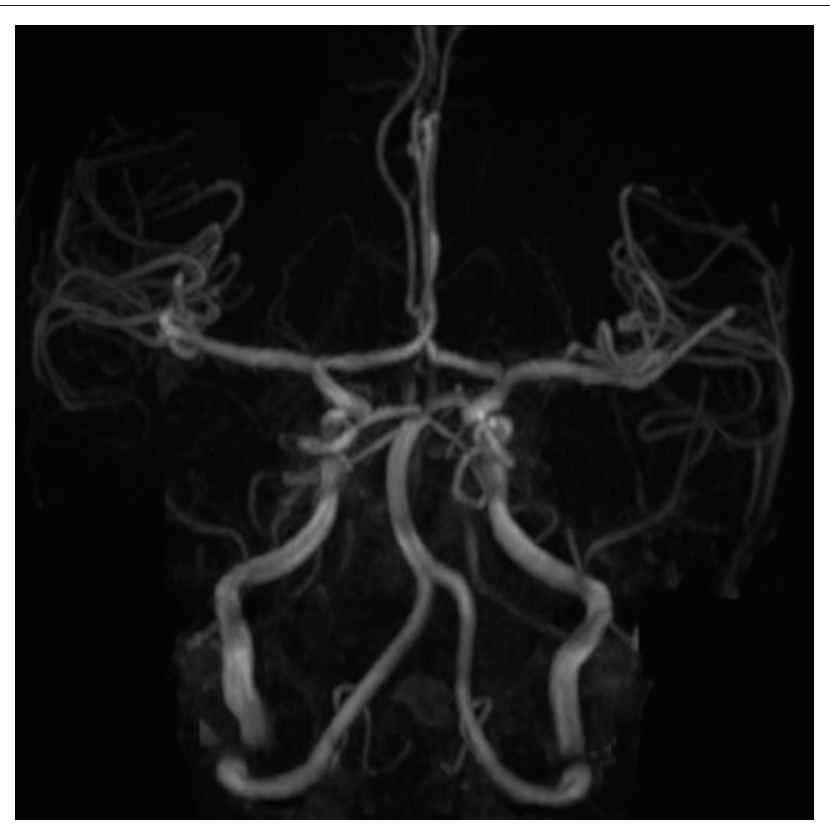

FIGURE 7: MR angiography image of the circle of Willis.

TABLE 1: Typical major and minor features of tuberous sclerosis.

\begin{tabular}{ll}
\hline Major features $\dagger$ & Minor features $\dagger$ \\
\hline Facial angiofibroma & Dental enamel pits \\
Cerebral cortical tubers & Rectal hamartomatous polyps \\
Hypomelanotic macules (three or more) & Bone cysts \\
Subependymal nodules & Cerebral transmantle migration lines \\
Retinal hamartoma & Gingival fibroma \\
Lymphangioleiomyomatosis & Renal cysts \\
Renal angiomyolipoma & Skin 'confetti' type lesions \\
Cardiac rhabdomyoma & Retinal achromic patches \\
Subependymal giant cell tumours & - \\
Ungual and/or periungual fibroma & - \\
Shagreen patches (connective tissue naevus) & - \\
\hline
\end{tabular}

Note: Definite diagnosis = 2 major $/ 1$ major +2 minor; Probable diagnosis $=1$ major + 1 minor; Possible diagnosis $=1$ major $/ 2$ or more minor

$\dagger$, In decreasing order of frequency. 
calcification and central cystic degeneration are infrequent features. Greater tuber load is associated with greater neurological fallout and poorer seizure control. Diffusion tensor imaging (DTI) of tubers shows lesions with reduced fractional anisotropy (FA) and increased mean diffusivity (MD). ${ }^{5}$

Subependymal nodules (SENS) are also hamartomatous in nature with a large proportion showing early calcification. These lesions are easily demonstrated on non-contrast CT scans or susceptibility-weighted imaging (SWI) or gradient echo sequences. See Figure 9, subtly showing the calcified SENS on a gradient echo sequence and Figure 10 demonstrating many more well-delineated calcified SENS in the patient reported here. Subependymal giant cell tumours or astrocytomas (SEGAS) are typically larger than SENS and occur particularly at the foramen of monro or the caudothalamic groove region. These are WHO Grade 1 tumours with slow progression, lack of local invasion, absence of surrounding oedema or cerebrospinal fluid (CSF) tumour seeding. mTOR pathway inhibitor Everolimus is an approved therapeutic agent for non-surgical management SEGAS.

Griffiths et al. ${ }^{6}$ described a spectrum of four types of white matter lesions found at MRI in TS complex. The commonest was spongiosis and hypomyelination related to cortical tubers. Transmantle bands or radial lines were less frequently identified in relation to cortical tubers, and these are probably heterotopic glia and neurons along the expected path of cortical migration. This glial scaffolding forms the basis of neuronal migration from the periventricular germinal matrix zone to the

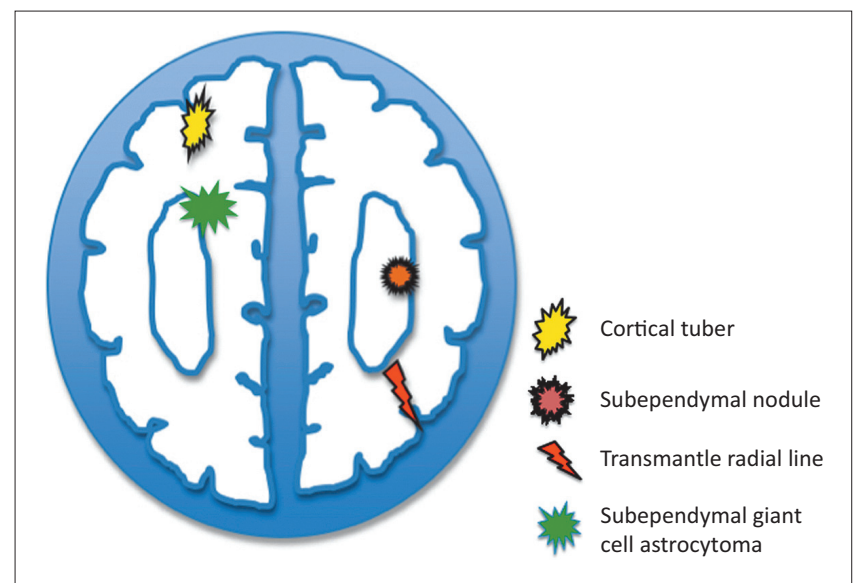

FIGURE 8: Schematic drawing depicting the location of the most common neuroimaging features of tuberous sclerosis. subcortical region and the eventual establishment of the sixlayered cerebral cortex. In a child, these radial bands appear hyperintense on T1-weighted and iso- or hypointense on T2weighted sequences relative to premyelinated white matter. In a minority of cases, these lesions are reported to show mild postgadolinium enhancement. ${ }^{7}$ DTI values are noted to be abnormal in radial migration lines correlating with the histological findings of clusters of giant cells of varying degrees of differentiation. ${ }^{8}$ TS is therefore the upshot of a dysgenetic event that occurs early in development with resultant variable cellular differentiation and hamartoma formation. DTI of white matter lesions has been listed as a biomarker for TS and for prognostication.

TABLE 3: Tuber subtypes based on MRI features in tuberous sclerosis and associated phenotypic presentation.

\begin{tabular}{lllll}
\hline $\begin{array}{l}\text { Tuber } \\
\text { type }\end{array}$ & T1 & T2 & FLAIR & Phenotype \\
\hline A & Isointense & Subtly hyperintense & Hyperintense & Mild \\
B & Hypointense & $\begin{array}{l}\text { Homogenously } \\
\text { hyperintense }\end{array}$ & Hyperintense & Moderate \\
C & Hypointense & hyperintense & Heterogeneous & $\begin{array}{l}\text { Poor clinical outcome. } \\
\text { Seizures ++ autism }\end{array}$ \\
\hline
\end{tabular}

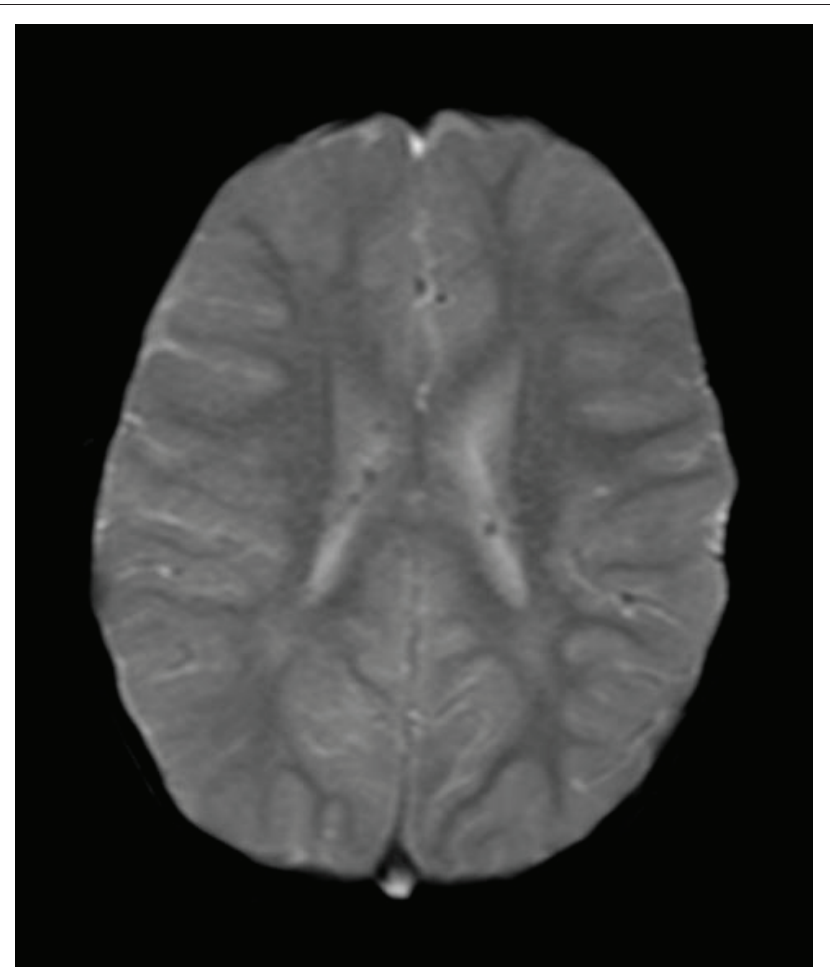

FIGURE 9: Gradient echo sequence image showing multiple subtle calcified subependymal nodules.

TABLE 2: Common neurologic features of tuberous sclerosis.

\begin{tabular}{lccl}
\hline Neurological feature & Incidence (\%) & Description and association \\
\hline Cortical and/or subcortical tubers & 70 & $\begin{array}{l}\text { Hypomyelinated hamartomas at cortex and subcortical white matter. Can be difficult to detect on foetal MRI and in } \\
\text { neonates. }\end{array}$ \\
Subependymal nodules & $80-90$ & $\begin{array}{l}\text { Hamartomas at outer walls of lateral ventricles. May be present in neonates. Best depicted on SWI and/or gradient echo } \\
\text { sequences or CT. }\end{array}$ \\
Subependymal giant cell astrocytomas & 15 & $\begin{array}{l}\text { Tumours usually located close to foramen of Monro, enlarging progressively into lateral ventricles. Heterogenous } \\
\text { enhancing mass. }\end{array}$ \\
Transmantle band sign & $10-15$ & $\begin{array}{l}\text { Radial white matter lesion from ependymal surface to subcortical plate. Can be associated with tuber or less frequently } \\
\text { not related to a tuber. Hyperintense band on FLAIR. }\end{array}$ \\
Other white matter lesions & $40-90$ & $\begin{array}{l}\text { Areas of T2-weighted sequence and FLAIR hyperintensity depicting foci of spongiosis or hypomyelination related to } \\
\text { cortical tubers. } \\
\text { Rare association with saccular or fusiform aneurysms of circle of Willis documented. }\end{array}$ \\
Aneurysms & $<5$ &
\end{tabular}



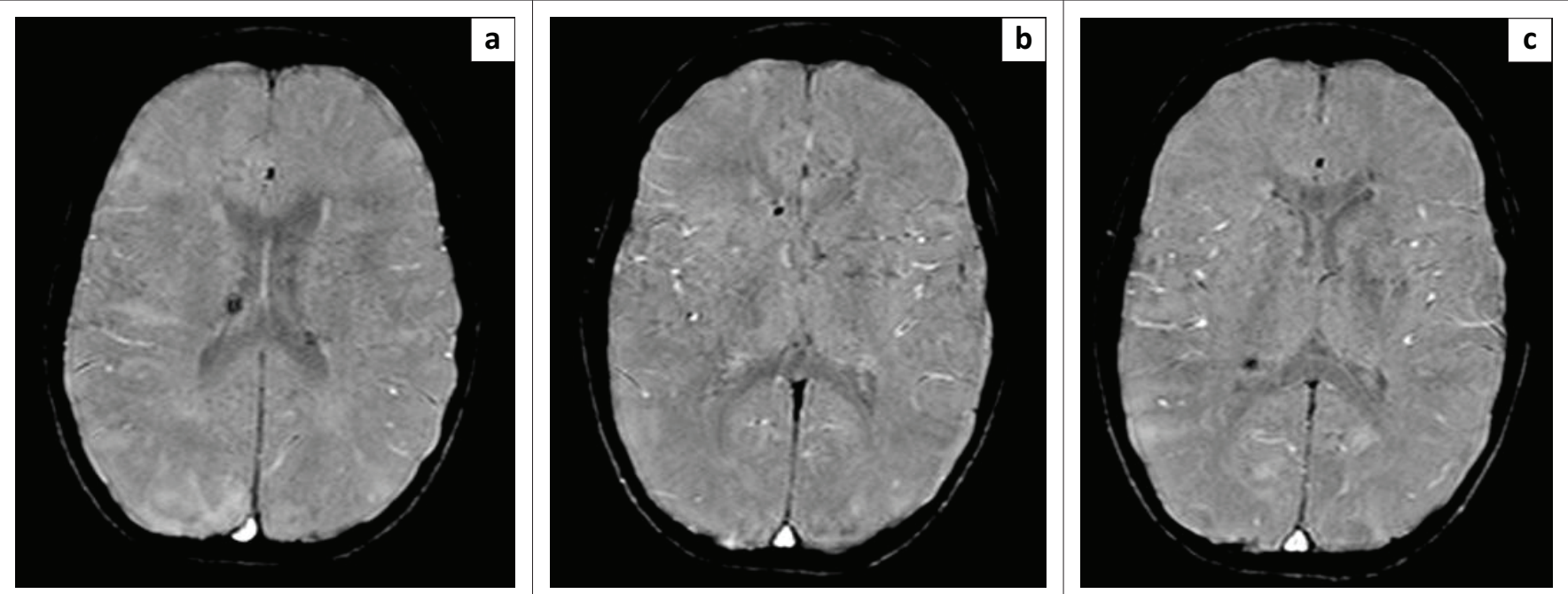

FIGURE 10: Susceptibility-weighted imaging sequence images showing multiple and more obvious calcified subependymal nodules (a, b and c).

Other white matter lesions described include white matter cysts and infarcts. Cyst-like white matter lesions described by Van Tassel et al. are typically located close to the lateral ventricles. ${ }^{9}$ These lesions are probably dilated perivascular spaces or they reflect areas of cystic degeneration related to focal gliosis or spongiosis. On all sequences, these white matter cystic foci remain iso-intense to CSF. Infarcts may be attributed to embolic aetiology or may be related to underlying vascular dysplasias that predispose to vascular occlusion. Rarely, moyamoya phenomenon or aneurysm rupture may be implicated in causing cerebral infarcts. ${ }^{6}$ Beltramello et al. ${ }^{10}$ recommended in 1999 that vascular dysplasias including intracranial aneurysms encountered in patients with TS be added to the other nonprimary diagnostic features for the clinical diagnosis of TS.

\section{Conclusion}

The coexistence of TS lesions and hippocampal sclerosis is an enigmatic phenomenon. It is not a frequently reported correlate. There are several theories to explain this occurrence. In the presence of an adjacent cortical lesion and white matter abnormality, hippocampal sclerosis may be a consequence of seizure activity induced by the tuber or MCD. This subtype of MCD has been classified according to Blümcke et al. ${ }^{11}$ as Type 3a (Figure 11). A further explanation for the coexistence of hippocampal sclerosis with adjacent cerebral cortical or subcortical lesions is the probability of a common pathogenetic mechanism that can be traced back along the path of neuronal migration. ${ }^{12}$

\section{Acknowledgements Competing interests}

The author declares that he has no financial or personal relationships which may have inappropriately influenced him in writing this article.

\section{References}

1. Leung AK, Robson WL. Tuberous sclerosis complex: A review. J Pediatr Health Care. 2007;21:108-114. http://dx.doi.org/10.1016/j.pedhc.2006.05.004
Classification of focal cortical dysplasia (FCD)
FCD Type I
Type la - Vertical dyslamination
Type lb - Horizontal dyslamination
Type Ic - Vertical and horizontal dyslamination
FCD Type II
Type Ila - Dysmorphic neurons
Type Ilb - Dysmorphic neurons with balloon cells
FCD Type III
IIIla = Hippocampal sclerosis $\quad$ IIIlb $=$ Tumour
IIIIc = Vascular malformation IIIId = Prior infection / Injury

FIGURE 11: Classification of focal cortical dysplasia (FCD).

2. Roach ES, Gomez MR, Northrup H. Tuberous sclerosis complex consensus conference: Revised clinical diagnostic criteria. J Child Neurol. 1998;13:624-628. http://dx.doi.org/10.1177/088307389801301206

3. Gallagher A, Grant EP, Madan N, Jarrett DY, Lyczkowski DA, Thiele EA. MRI findings reveal three different types of tubers in patients with tuberous sclerosis complex. J Neurol. 2010;257(8):1373-1381. http://dx.doi.org/10.1007/s00415010-5535-2

4. Baron $\mathrm{Y}$, Barkovich AJ. MR imaging of tuberous sclerosis in neonates and young infants. AJNR Am J Neuroradiol. 1999;20:907-916.

5. Peters JM, Taquet M, Prohl AK, et al. Diffusion tensor imaging and related techniques in tuberous sclerosis complex: Review and future directions. Future Neurol. 2013;8(5):583-597. http://dx.doi.org/10.2217/fnl.13.37

6. Griffiths PD, Bolton P, Verity C. White matter abnormalities in tuberous sclerosis complex. Acta Radiol. 1998;39:482-486. http://dx.doi.org/10.1080/02841859809 172211

7. Bernauer TA. The radial bands sign. Radiology. 1999;212(3):761-762. http:// dx.doi.org/10.1148/radiology.212.3.r99se17761

8. Caruso P. The neuroanatomical phenotype of tuberous sclerosis complex: Focus on radial migration lines. Neuroradiology. 2013;55(8):1007-1014. http://dx/doi. org/10.1007/s00234-013-1184-3

9. Van Tassel P, Cure JK, Holden KR. Cystlike white matter lesions in tuberous sclerosis. AJNR Am J Neuroradiol. 1997;18:1367-1373.

10. Beltramello A, Puppini G, Bricolo A, et al. Does tuberous sclerosis complex include intracranial aneurysms? A case report and review of the literature. Pediatr Radiol. 1999;29:206-211. http://dx.doi.org/10.1007/s002470050573

11. Blümcke I, Thom M, Aronica E, et al. The clinicopathologic spectrum of focal cortical dysplasias: A consensus classification proposed by an ad hoc Task Force of the ILAE Diagnostic Methods Commission. Epilepsia. 2011;52(1):158-174. http:// dx.doi.org/10.1111/j.1528-1167.2010.02777.x

12. Kier EL, Kim JH, Fulbright RK, Bronen RA. Embryology of the human fetal hippocampus: MR imaging, anatomy, and histology. AJNR Am J Neuroradiol 1997;18:525-532. 